\title{
Potential detection of water resources in karst formations using APLIS model and modification with AHP and TOPSIS
}

\author{
Mahnaz ZareE $^{1}$, SAman JAVAdi ${ }^{2, *}$ and AminReZa Neshat ${ }^{3}$ \\ ${ }^{1}$ Department of Civil Engineering, Science and Research Branch, Islamic Azad University, Tehran, Iran. \\ ${ }^{2}$ Department of Irrigation and Drainage Engineering, Aburaihan Campus, University of Tehran, Tehran, Iran. \\ ${ }^{3}$ Department of GIS/RS, Faculty of Natural Resources and Environment, Science and Research Branch, \\ Islamic Azad University, Tehran, Iran. \\ *Corresponding author.e-mail: Javadis@ut.ac.ir
}

MS received 31 July 2017; revised 14 August 2018; accepted 29 October 2018; published online 20 March 2019

Population growth and water shortage in Iran have highlighted the importance of studies on karst. However, in developing countries such as Iran, studies on the karst region including the construction of piezometric wells, exploratory boreholes, qualitative sampling and tracing tests are performed infrequently due to the huge costs. Hence, it is necessary to conduct karst studies in regions with a high potential of recharge using the map of groundwater recharge potential. In addition, determining and estimating the potential of these resources for management planning is vital in water shortage conditions. In this study, the potential detection of water resources in karst formations using ranking methods is investigated. First, APLIS weighting model was used in Javanroud, Kermanshah region, as the main method of and the basis of this research. Then, analytic hierarchy process (AHP) and TOPSIS techniques were used to modify the weight of the APLIS model and lastly, the three final maps of APLIS, AHP and TOPSIS were matched and compared with maps of spring and fault. Thus, the TOPSIS method, despite five springs with discharge of $38 \mathrm{~m}^{3} / \mathrm{s}$ and four faults with length of $8869 \mathrm{~m}$ in a region with very high recharge, was selected as the best method. The results obtained enable us to select the best region for geophysical operation that requires the least amount of time along with the lowest cost.

Keywords. Karst; potential detection; weighting method; Javanroud Kermanshah; decision-making model.

\section{Introduction}

Almost one-fifth of the Earth's surface is covered by different carbonate formations (Lamoreaux 1991). On the other hand, more than $25 \%$ of the world's population lives in karst areas or get their needed water from karst resources (Ford and Williams 2013). In Iran, approximately $11 \%$ of the whole country and about $90 \%$ of the Zagros highlands are composed of karst formations (Mohammadi and Field 2009). Water quality has been emphasised in groundwater management (Neshat et al. 2014a, b; Kardan Moghaddam et al. 2017; Neshat and Pradhan 2017). Due to Iran's unique climate conditions, rainfall shortage and inadequate spatial distribution and timing as well as limited 
water resources in terms of quality and quantity, and widespread expansion of karst formations throughout the country, studies on karst water resources have become crucial (Yeh et al. 2009; Gerner et al. 2012). The term karst defines a unique morphological and hydrological feature in soluble rocks, such as carbonate and evaporite rocks, which can lead to the formation of an aquifer. Such a phenomenon is related to the existence of fractures and solubility of the rock where a groundwater system can be formed. Thus, the formation of a karst feature depends on two factors: first, the solubility of rock mass; and second, the possibility of forming a groundwater system. Downward flow of water to the water table and groundwater reservoir is referred to as recharge. Over a fairly long period and in aquifers not constrained to pumped reactions, the rate of discharge is the same as the mean annual value of the recharge. For this reason, the groundwater recharge covering an area is the same as the infiltration excess. Three mechanisms of discharge are as follows (Lerner et al. 1990): direct discharge by means of percolation through the zone i.e., unsaturated, indirect recharge within beds of surface-water courses and localised or concentrated recharge at points. We can declare the aquifer to be an annual mean volume, which is usually called mean annual resource or entry, or as a percentage of precipitation. This can be referred to as the rate of recharge or effective infiltration.

Numerous studies have been conducted in this regard, including the research conducted by Andreo et al. (2008) who estimated the surface recharge using the APLIS method for the first time, due to lack of access to sufficient data. The results of this study led to the spatial distribution of recharge in the region of Javanroud, Kermanshah. In terms of international and regional water governance policies, the evaluation of groundwater recharge plays a vital role (Gleeson et al. 2012). The consequences of various emission scenarios on recyclable groundwater resources were examined by Portmann et al. (2013). A decline of more than $30 \%$ in groundwater recharge was observed specifically in the semi-arid regions and from every climate model (Portmann et al. 2013). The probability of the Mediterranean area and its groundwater resources being affected by climate change is high (Giorgi and Lionello 2008). In comparison with other regions of the world, karst regions are proved to be a significant source of drinking water (Ford and Williams 2013), and doubts occur with regard to the estimation of their hydrological behaviour within the changing climate (Hartmann et al. 2014).

In another study, Andreo et al. (2008) studied the assessment of karst groundwater supply by APLIS and potential detection at a European scale. They concluded that the APLIS method is a potentially useful tool for groundwater recharge and water resource assessment and spatial distribution in carbonate aquifers. Field studies indicate that the region has weak degree of karstification processes and springs emerge in the points with maximum potential in the southern part of the region (Andreo et al. 2008).

To access the exact location of water resources, geophysical methods are used which are considered as the most accurate methods. However, due to high cost of geophysical operations in a wide area, potential detection of water resources should be evaluated at first. Hence, in this study, the potential detection of water resources in karst formations was studied using various ranking methods. According to the possibility of mapping, the spatial distribution of recharge rate inside aquifers is consistent with their individual features, and especially when focusing on carbonate aquifers, the APLIS method was preferred. The application of this technique has been successful in a vast number of Spanish karst aquifers (Andreo et al. 2007; Martos-Rosillo et al. 2009; Andreu et al. 2011; Guardiola-Albert et al. 2015). Furthermore, the application of APLIS method in karst aquifers has been made possible in a number of countries (Farfan et al. 2010; Gerner et al. 2012).

With this contribution, through application of the APLIS method, the autogenic groundwater recharge in Javanroud, Kermanshah region, was measured and modified using analytic hierarchy process (AHP) and TOPSIS, and the outputs of which were chosen by means of data gathered from the faults and springs.

\section{Materials and methods}

\subsection{Geographical location and geology}

The study area, Javanroud, Kermanshah region, is located at $29.8^{\circ} \mathrm{N}$ and $48.5^{\circ} \mathrm{S}$. It covers an area of $1251 \mathrm{~km}^{2}$ of the catchment basin of Ab Leyleh-Ab Sefid Barg River. This area is located in a mountainous place, and the average annual rainfall in this region is $600 \mathrm{~mm}$ and the evaporation rate is 1850-1912 mm. Moreover, the average height of the 


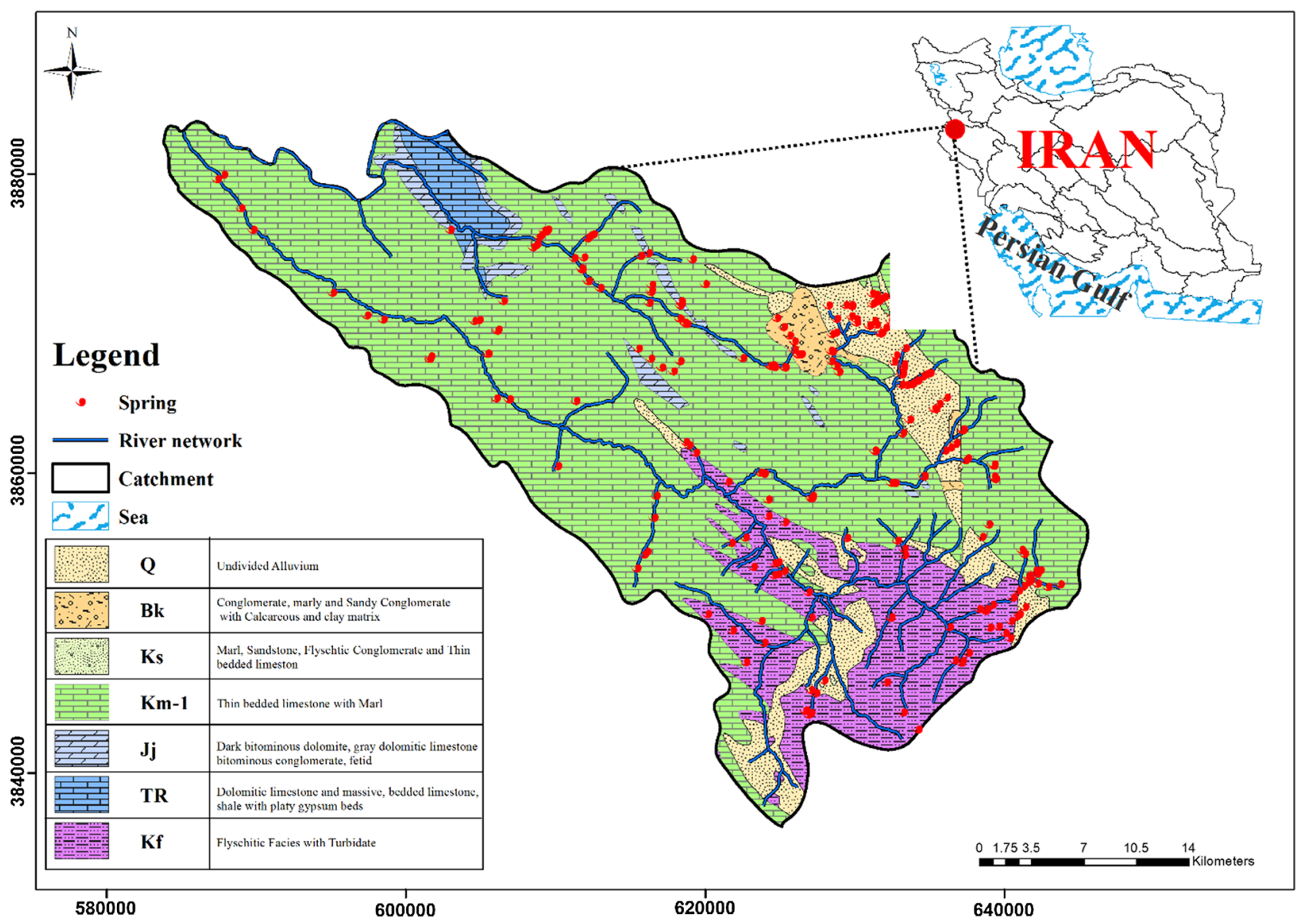

Figure 1. Map of geographical location and geology of study area in Javanroud, Kermanshah Province.

basin is $1905 \mathrm{~m}$ above sea level. Figure 1 shows the study area of Javanroud, Kermanshah region, in terms of geographical location.

Geology of the study area is shown in figure 1 . As it is seen, most of the areas except the southern parts are composed of a thin layer of calcareous formation and the southern parts of the region include the destructive and turbidite layers, unclassified alluviums, dark coal dolomite, dark dolomite limestone and coal conglomerates. Moreover, a limited area in the northern part consists of coal dolomite formation, dark dolomite limestone, coal conglomerate, sandy conglomerate and a mixture of limestone and clay (Bakhtiari formation). In addition, it has carbonate rock formation, pile and layered limestone as well as layers of silica and radiolarites, characterised by a remarkable capability to store water (figure 1).

Many factors affect the collection of water reservoirs in karst regions, including sufficient rainfall, tectonic factors, lithology compound, existence of limiting formations, and expansion and thickness of karst topography. Concerning the rainfall, it is evident from the data that precipitation in the region is significant such that the average annual rainfall in most of the regions is more than 500 $\mathrm{mm}$. On the other hand, the primary condition to penetrate precipitation into any rock formations is the existence of crack system, the movements and pressures resulted from tectonic activities and orogenies prepare the ground for it. As such, numerous joint systems have been created in the carbonate rock formations in this region as a result of intense tectonic and orogenesis movements, and these systems are effective in penetration of a significant amount of precipitation into the deeper layers. The mild folds of these formations are also effective in penetration of precipitation. On the other hand, as the purity grade of carbonate rocks is increased and free from impurity, the solubility of their karstification process will also be increased. This fact holds true in carbonate formations especially in Bistoon formation where both the surface and deep karstic phenomena are abundantly observed. One 
reason for accumulation of penetrated water in hard formations is due to the existence of limiting impermeable formations below and in vicinity of them. In the study area, the Gachsaran impermeable formation below and in the vicinity of carbonate formation inhibit the flow of water to distant areas, and thus, a good condition is created for water storage. In general, the accumulated waters in carbonate formations in contact point with limiting formations overflow in the form of springs. Finally, the expansion and thickness of karstic formations are the other factors that affect the creation of water reservoirs in hard formations.

In the Javanroud study area, carbonate destructive colloidal formations and carbonate colloidal formations are widely expanded and carbonate formations expand less, such that it is estimated that a total number of 60 springs with annual discharge of 7.5 million $\mathrm{m}^{3}$ emerge from carbonate formations, whereas the number of springs emerging from other hard formations is 493 with annual discharge of 161.2 million $\mathrm{m}^{3}$.

\subsection{APLIS method}

The evaluation of the rate of autogenic recharge into carbonate aquifers, on the basis of a mixture of geological, geographic, morphologic and edaphologic variables, is conducted by APLIS (Marín 2009; Andreu et al. 2011). Effective factors such as height above sea level $(A)$, slope $(P)$, lithology $(L)$, penetration $(I)$ and soil cover $(P)$ were considered, and GIS software was used in the overlay and analysis of information layers. The mean recharge is proportional to precipitation because the constant of proportionality in terms of each aquifer is a must, as a function of its intrinsic variables. A score from 1 to 10 was allotted to each variable succeeding an arithmetic progression (in terms of minimal incidence on aquifer recharge: 1 ; and in terms of maximum influences on recharge: 10). A map was created to analyse and construct layers using the received data, and then by using ranking related to the APLIS method, the ranked and classified layers were prepared. Finally, using the data integration formula, the final map related to APLIS was prepared and the spatial distribution of groundwater recharge of these layers was modelled. The ranking of effective layers in penetration rate is shown in table 1 and

$$
R=[(A+P+3 L+2 I+S) / 0.9] .
$$

\subsection{AHP technique}

AHP technique, introduced by Saati in 1980, is a method used for karst potential detection. In this study, the weight of the APLIS method changes and the final potential map is checked and prepared in GIS using the AHP technique. First, a map to analyse and construct the layers is produced using the received data, and then, for the purpose of AHP-related weighting, the weighted and classified layers are prepared by questionnaire method.

One basic measurement method to apply AHP process is pair comparisons. This method considerably reduces the conceptual complexity of decision making because only two decision-making elements are checked at a time. This method is conducted in the following three stages:

(i) to prepare pair comparison at each level of the hierarchy, which starts from the top and continues to the bottom;

(ii) to calculate weights of each elements in hierarchy;

(iii) to estimate a compatibility rate.

Thus, if we assume that the hierarchy is composed of the main goal, objectives, characteristics and options, then this method is performed for three levels of objectives, characteristics and options. Each pair comparison is created to estimate the weight of relative importance of each element at a particular level by observing the elements of a higher level. One of the basic assumptions of AHP is the compatibility in the values of the judgements made for levels of options and characteristics in the decision-making process. Note that the paired comparisons are only used in a relatively small number of elements at every level of the decision-making hierarchy. Thus, it can only be used for issues containing a relatively low number of options. When a large number of options are examined, then AHP ends in the characteristic level because all options in the cell should be examined. All weights of characteristics are allocated to the layer of characteristic map and processed in GIS.

\subsection{TOPSIS technique}

Another method to modify the weighting model of potential detection of karst water resources is TOPSIS technique, which was introduced by Yong Huang in 1981. The TOPSIS technique for order of preference by similarity to ideal solution is a multicriteria decision-making method like AHP. This 


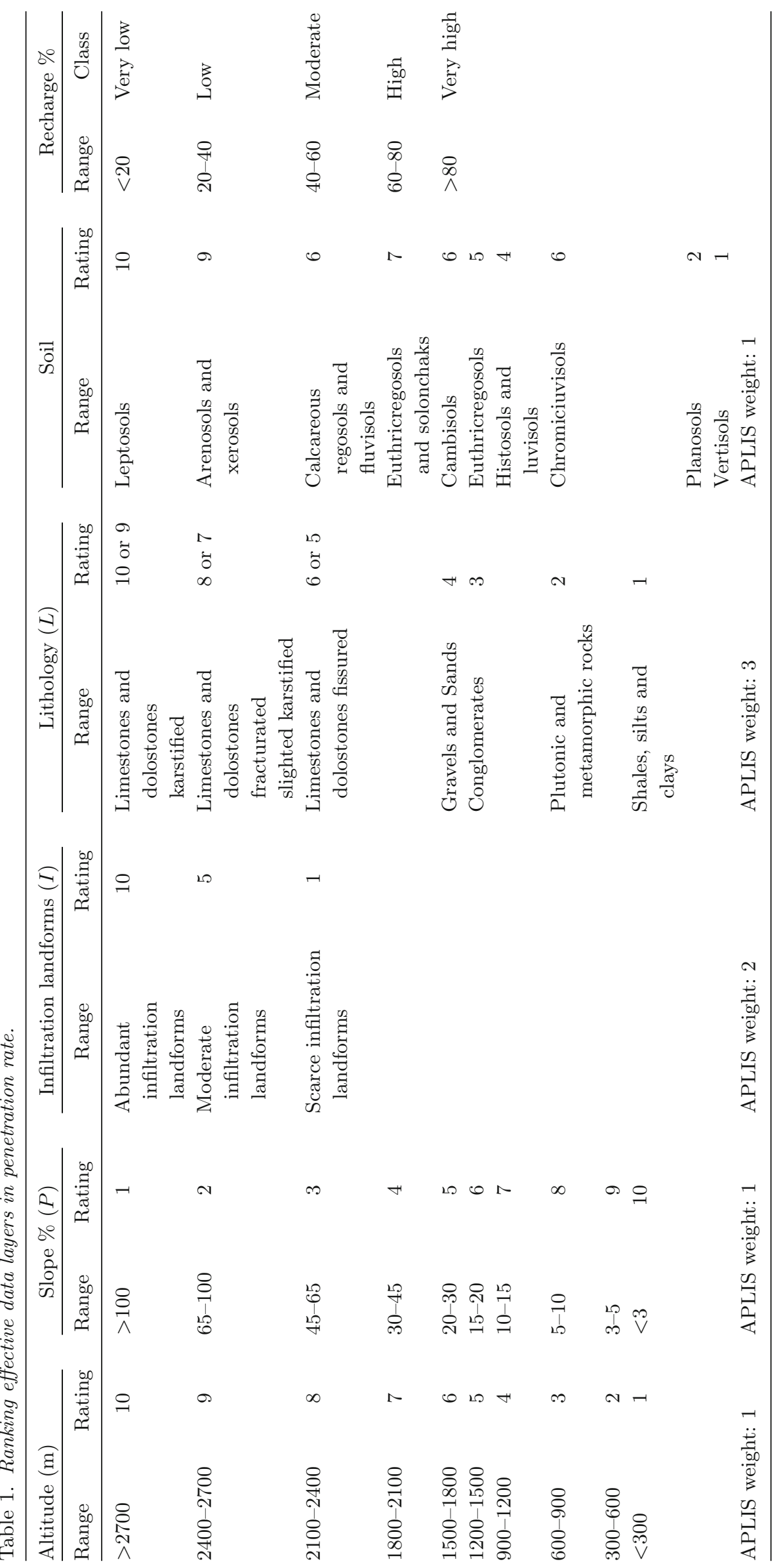


technique can be used to rate and compare various options, to choose the best one and to determine the intervals between the options and classifying them. Among the advantages of this method is that the criteria or indicators used for comparison can have different measurement units as well as both positive and negative natures. The steps to implement this method are as follows:

Step 1: The numeric value of classified layers in selected points should be extracted from the map and a matrix is developed with criteria in column and options in a row. (We suppose that $i$ and $j$ are row and column of a given matrix, respectively, with $n$ options and $m$ variables.)

Step 2: A non-dimensional matrix is created. To non-dimensionalise the matrix, at first place, it should be calculated by a formula. The nondimensional data means converting them to the numbers between zero and one. The score of each value should be obtained by $\left(a_{i j}\right.$ are the numbers in the decision-making matrix and $n_{i j}$ are the numbers in the non-dimensional matrix.)

$$
n_{i j}=\frac{a_{i j}}{\sqrt{\sum_{i=1}^{m} a_{i j}^{2}}} .
$$

Step 3: This step involves the extraction of positive and negative ideals for each index. Values of these positive and negative ideals in this study are presented for decision making in equations (3) and (4). The best values for positive index are the largest values, and for negative index, it is the smallest ones. Similarly, the worst values for positive index are the smallest values, and for negative index, the worst values are the greatest ones. ( $V$ is equal to the number of weighted nondimensional matrices; and $a, p, l, i$ and $s$ are the five variables used in the present study.)

$$
\begin{aligned}
J^{+}= & {\left[\max V_{j a}, \min V_{j p}, \max V_{j l}, \max V_{j i},\right.} \\
& \left.\max V_{j s}\right], \\
J^{-}= & {\left[\min V_{j a}, \max V_{j p}, \min V_{j l}, \min V_{j i},\right.} \\
& \left.\min V_{j s}\right] .
\end{aligned}
$$

Step 4: This step involves estimating the distance of each option from positive and negative ideals (equations 5 and 6).

$\left(v_{j}^{+}\right.$is the positive ideal of each criterion, $v_{j}^{-}$is the negative ideal of each criterion, $v_{i j}$ are the number of weighted non-dimensional matrices, $d_{j}^{+}$is the distance of each option from positive ideal and $d_{j}^{-}$is the distance of each option from negative ideal.)

$$
\begin{aligned}
& d_{j}^{+}=\sqrt{\left(\sum_{j=1}^{m} v_{i j}-v_{j}^{+}\right)^{2}}, \\
& d_{j}^{-}=\sqrt{\left(\sum_{j=1}^{m} v_{i j}-v_{j}^{-}\right)^{2}} .
\end{aligned}
$$

Step 5: At this stage, in equation (7), the relative proximity of each option to ideal solution is calculated. The estimated value is a number between 1 and $0\left(\mathrm{cl}_{i}^{+}\right.$ranking options).

$$
\begin{gathered}
\mathrm{cl}_{i}^{+}=\frac{d_{i}^{-}}{d_{i}^{+}+d_{i}^{-}} ; \quad 0 \leq \mathrm{cl}_{i}^{+} \leq 1 ; \\
i=1,2, \ldots, m
\end{gathered}
$$

Step 6: According to equation (8) and CL values, ranking the options is performed (the closer value to 1 is appropriate and closer to zero is inappropriate):

$$
\mathrm{CL}_{2}>\mathrm{CL}_{5}>\mathrm{CL}_{1}>\mathrm{CL}_{3}>\mathrm{CL}_{4} \text {. }
$$

Finally, selected weights in this study are obtained by the TOPSIS technique and the final map of water potential is prepared and checked in GIS (figure 2).

\section{Results and discussion}

\subsection{Map of APLIS potential detection}

On the basis of the data collected from different references in map format, raster is prepared, and each map is produced for different classes based on ranking APLIS method. Ranking related to different parameters is presented in table 1 . All the output maps of the parameters of the APLIS model are presented in figure 3. According to the map of height above sea level, the more height above sea level, the penetration will be more and so it is of great importance. It should be noted that the study area has a minimum height of $464 \mathrm{~m}$ and maximum height of $3346 \mathrm{~m}$. On the other hand, less penetration occurs in the steeper regions. Therefore, according to the map, the slope is of great importance in the regions with less steep. The study area has a minimum slope of $0 \%$ and a maximum slope 


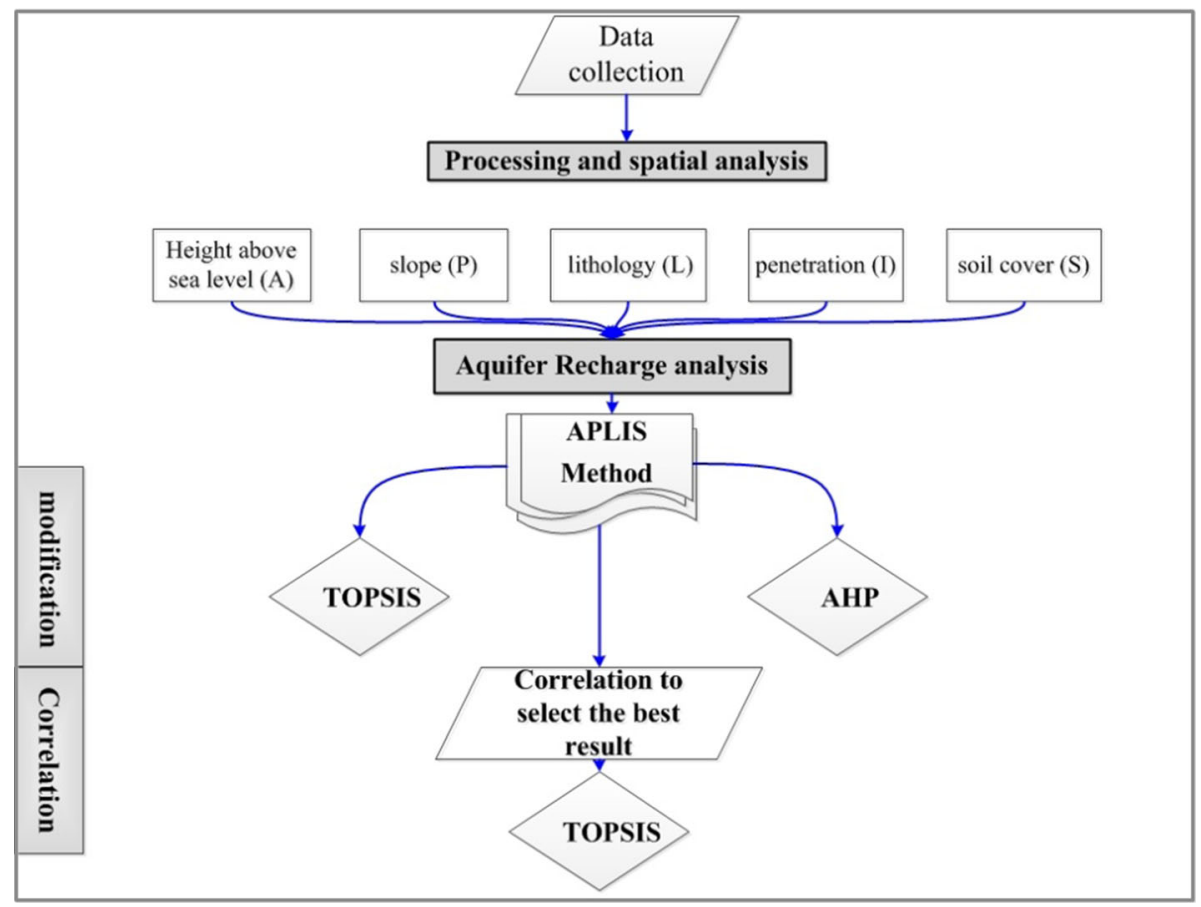

Figure 2. Overall methodology of this study.

of $80 \%$. In addition, with respect to lithology map, the greater amount of limestone indicates higher ranking. As shown in the map, the northern and southern parts have more lime and thus have a higher ranking. Moreover, regarding the penetration map, the more penetration, the ranking will be higher. As shown, most regions except areas in the northeast and southeast are characterised by more penetration and therefore have a higher ranking. According to the agrology map, a smaller amount of soft immature soils indicates a higher ranking. As shown, most regions except the eastern parts have more penetration and therefore have a higher ranking. After creating five layers in GIS, the final step includes the integration of APLIS layers, incorporating effective layers using equation (1). It suggests that the largest area belongs to a region with a very low recharge $(<20 \%)$.

\subsection{APLIS modification with AHP technique}

At first, the AHP technique is used to modify AHP. As such, the weights of APLIS method are changed and the final potential map is prepared and checked in GIS. Firstly, using the received data, the required map for the analysis and construction of layers is produced. Secondly, for AHPrelated weighting, the weighted and classified layers are prepared by questionnaire method. The weights obtained by the AHP technique are presented in table 2. Then, to create the final map using the
AHP technique, five layers (variables) are integrated. Figure 4 shows that in this area, the region with the average recharge of $40-60 \%$ covers the largest area.

\subsection{APLIS modification with TOPSIS technique}

After using the AHP technique, the TOPSIS technique was applied to modify the weights. Similar to AHP technique, TOPSIS changes the APLIS weights as well. In the TOPSIS method, five areas were selected as samples and numeric values of layers were extracted. Finally, using the TOPSIS technique, five sample areas were ranked and the final map of figure 5 was obtained. With respect to the final map, the greatest area belongs to a region with an average recharge of $40-60 \%$.

\subsection{Comparison of final maps}

Despite the widespread use of ranking methods such as APLIS and KARSTLOP in determining the degree of recharge in a karstian region, these methods have some shortcomings and limitations. The most important weakness of these models is using the fixed weights for their parameters, such that similar weights and ranks are designated to different studied regions, irrespective of their hydrogeological characteristics. For example, in a region with appropriate soil coverage, this parameter has the least weight in the APLIS method. 


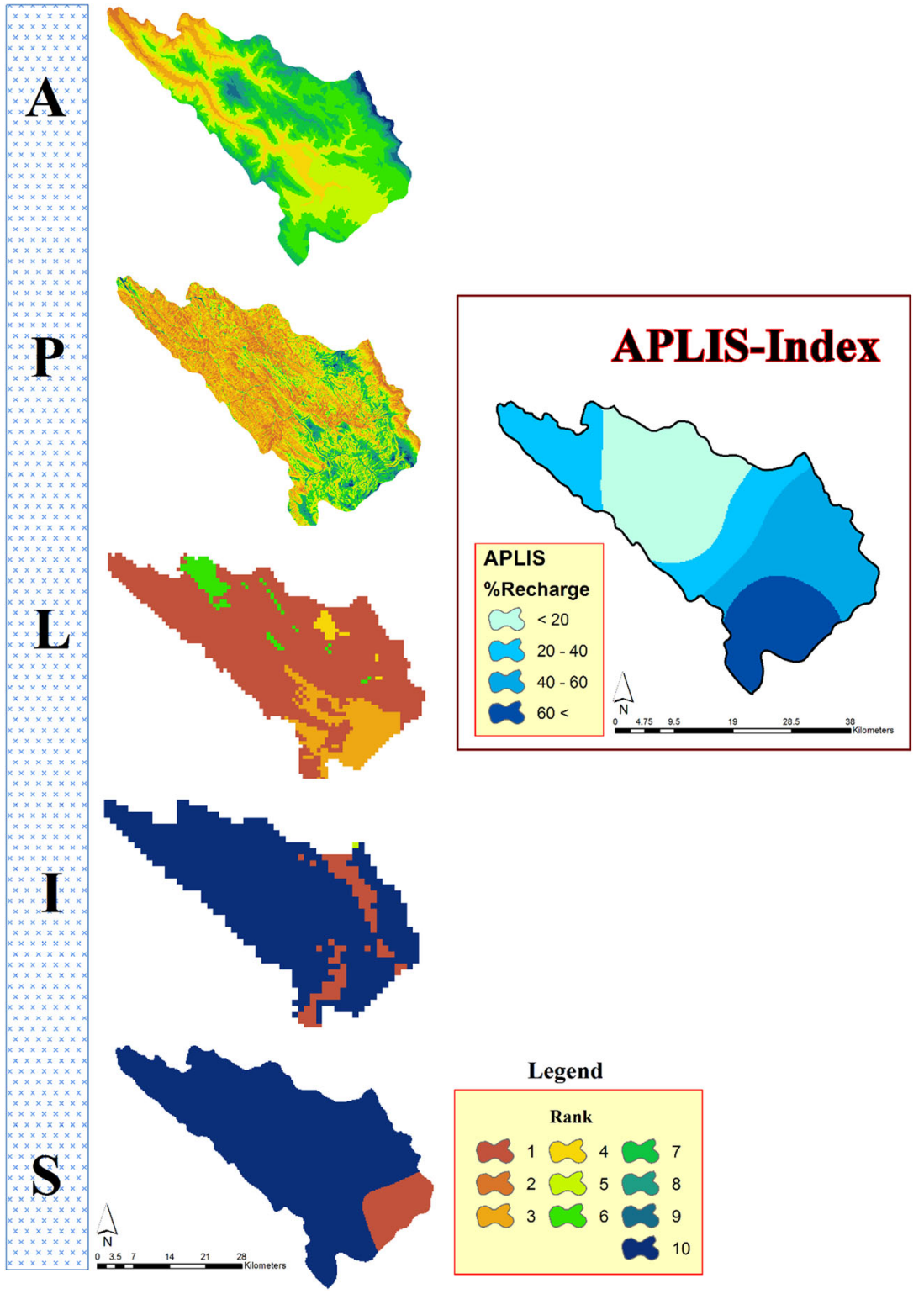

Figure 3. Produced layers using ranking APLIS method.

Table 2. Weight of each variable using the AHP technique.

\begin{tabular}{lccccc}
\hline Layers & $\begin{array}{c}\text { Height above } \\
\text { sea level }\end{array}$ & Slope & Lithology & Penetration & Soil cover \\
\hline AHP & $0 / 33$ & $0 / 2$ & $0 / 15$ & $0 / 14$ & $0 / 17$ \\
\hline
\end{tabular}

Therefore, to gain more accurate estimations of the results, it is necessary to modify the APLIS method using multi-criteria decision-making models such as AHP and TOPSIS due to their widespread use, ease of analysis and high accuracy. In spite of the advantages of AHP method in modification of APLIS, it can be referred to expert opinions who are familiar to the region. In other words, the experts who complete the pair comparison questionnaire have a good grasp of all criteria and parameters of APLIS method as well as the study area. Furthermore, the TOPSIS method, in addition to advantages of AHP model in using expert opinions, enjoys other strengths including weighing and making preference by logic of similarity to ideal solution.

As APLIS is a ranking method, it is required to be modified for the study area, and thus, in this study, the AHP and TOPSIS techniques have been used to modify the APLIS method. For this 


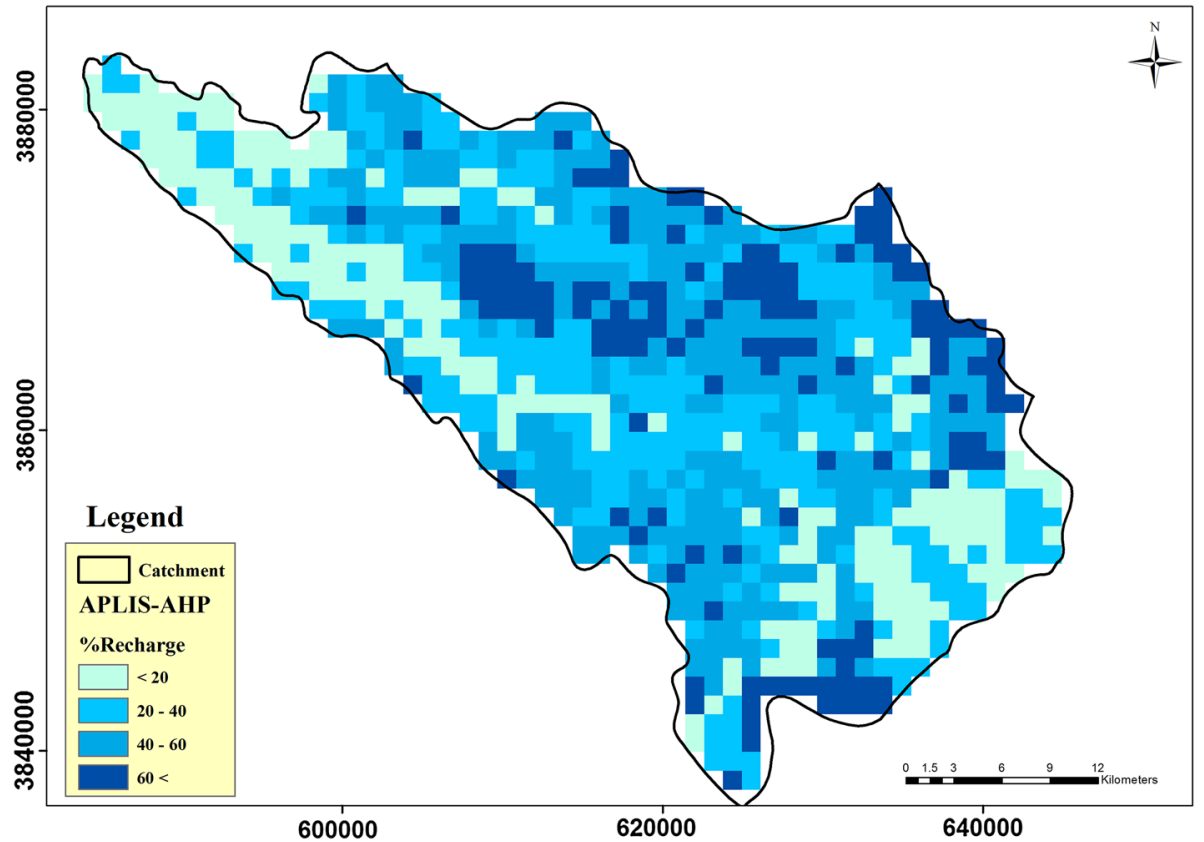

Figure 4. APLIS modification using AHP method.

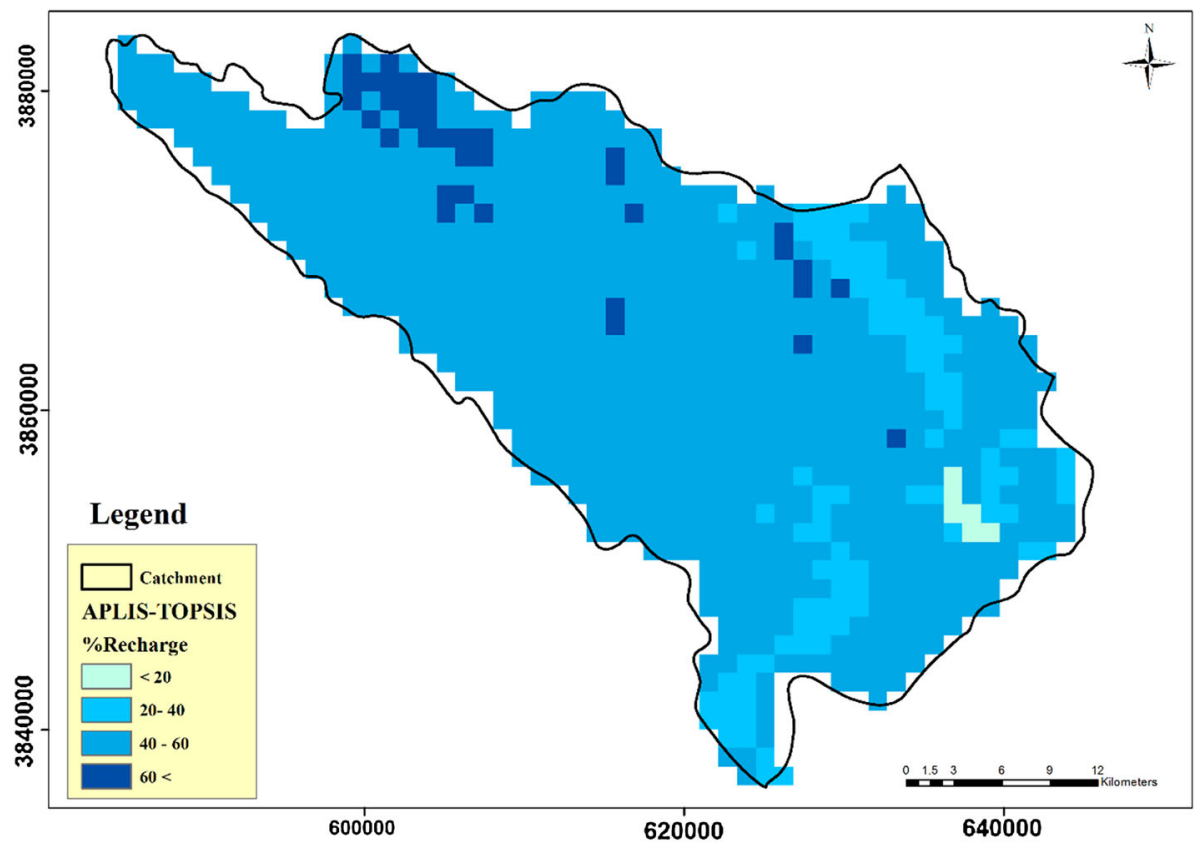

Figure 5. APLIS modification using TOPSIS method.

purpose, three maps of groundwater recharge potential zone were produced to select the best method finally. In the next step, authenticity of the prepared maps should be determined in terms of number and discharge of springs as well as the fault lines. In other words, the more number and discharge of springs in an area, the higher will be recharge in that area. On the other hand, most of faults are organised in a way such that in a region with higher number of faults, the penetration of groundwater is increased.

To compare three weighting methods, two characteristics, i.e., the positions of the fault and spring were checked and the map of each was prepared. Then, each final map of the APLIS, AHP and TOPSIS methods was matched using ARCGIS software on two characteristics and the position of each was checked, as shown in figure 6 . To compare 

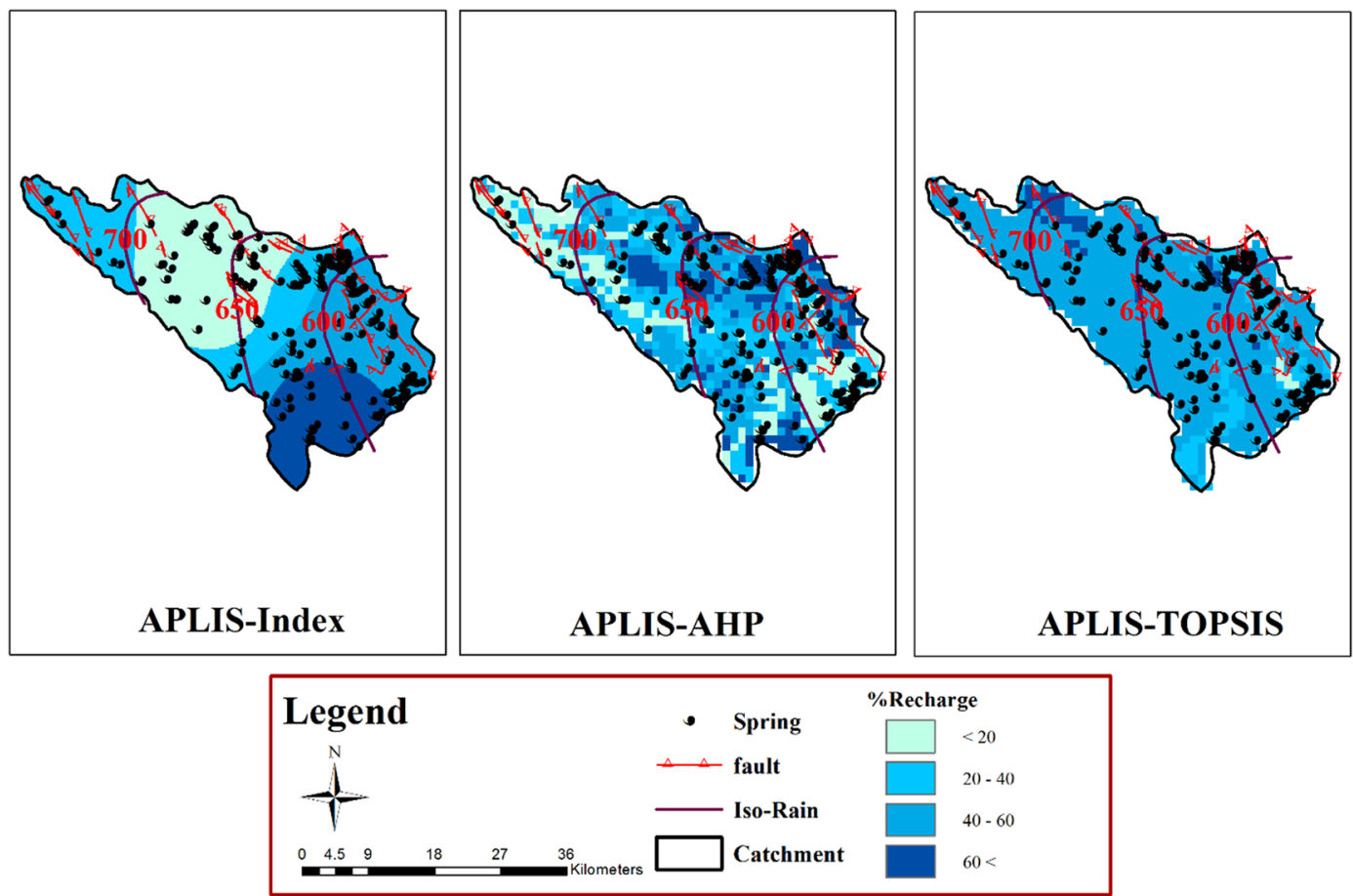

Figure 6. Comparison of three APLIS, AHP and TOPSIS methods by matching fault and spring.

Table 3. Comparison of results of APLIS, AHP and TOPSIS methods by matching fault and spring map.

\begin{tabular}{|c|c|c|c|c|c|c|}
\hline \multirow{2}{*}{$\begin{array}{l}\text { Method } \\
\text { Recharge }\end{array}$} & \multicolumn{2}{|c|}{ APLIS } & \multicolumn{2}{|c|}{$\mathrm{AHP}$} & \multicolumn{2}{|c|}{ TOPSIS } \\
\hline & Spring & Fault & Spring & Fault & Spring & Fault \\
\hline \multicolumn{7}{|c|}{ In terms of number } \\
\hline Very low & 59 & 7 & 44 & 9 & 0 & 2 \\
\hline Low & 57 & 9 & 109 & 13 & 55 & 8 \\
\hline Medium & 98 & 9 & 45 & 14 & 140 & 21 \\
\hline High & 7 & 2 & 46 & 12 & 5 & 4 \\
\hline \multicolumn{7}{|c|}{ In terms of unit } \\
\hline Very low & 698 & 36,488 & 485 & 39,391 & 0 & 1995 \\
\hline Low & 1171 & 48,390 & 1884 & 28,995 & 1118 & 22,012 \\
\hline Medium & 1751 & 49,720 & 650 & 40,540 & 3413 & 101,423 \\
\hline High & 217 & 2493 & 1565 & 27,203 & 38 & 8869 \\
\hline
\end{tabular}

Fault unit is metre and spring unit is cubic metre per second.

the weighting APLIS, AHP and TOPSIS methods, all the results obtained by the three methods are presented in table 3 . The results obtained from three techniques to determine the recharge extent of Javanroud area are presented in table 4 and show that in general, the region has high potential of groundwater recharge. According to this table, in all the three methods, the high and medium recharges are more than $40 \%$. This high value represents the importance of groundwater in karst regions.

The results calculated by matching the TOPSIS weighting model with the fault and spring map
Table 4. Comparison of area percentage in APLIS, AHP and TOPSIS methods.

\begin{tabular}{lccc}
\hline Recharge ranges & TOPSIS & APLIS & AHP \\
\hline Very low & 2 & 32 & 22 \\
Low & 10 & 25 & 30 \\
Medium & 84 & 25 & 32 \\
High & 4 & 18 & 16 \\
\hline
\end{tabular}

in Javanroud, Kermanshah region, showed that in the area with high recharge $(4 \%)$, there were five springs with a discharge of $38 \mathrm{~m}^{3} / \mathrm{s}$ and four fault 
lines with a length of $8869 \mathrm{~m}$. Moreover, the results obtained by matching the AHP map with the fault and spring map in Javanroud, Kermanshah region, showed that in the region with high recharge (16\%), 46 springs had a discharge of $1565 \mathrm{~m}^{3} / \mathrm{s}$ and 12 fault lines had a length of $27,203 \mathrm{~m}$. Given that it covers a small area, aggregation of spring and fault is observed in this region. According to the results obtained by matching the APLIS map with the fault and spring map of Javanroud, in the region with high recharge $(18 \%)$, seven springs had a discharge of $217 \mathrm{~m}^{3} / \mathrm{s}$ and two fault lines had a length of $2493 \mathrm{~m}$.

Therefore, in this study, having classified the output maps resulted from three techniques including APLIS, AHP and TOPSIS and compared them with fault and spring, the TOPSIS was selected as the best method. As such, with the least level of high recharge (i.e., 4\%), the maximum discharge of spring and fault line is aligned to.

In addition, in order to determine the best proposed method, the rainfall variations in different points of the region were matched with recharge maps and the results suggest that the TOPSIS method was highly correlated with rainfall level, such that in groundwater recharge map prepared by TOPSIS method, the maximum rainfall (700 $\mathrm{mm})$ coincided with the regions with high recharge.

\section{Conclusion}

In this study, application of a new approach to measure the quantity of groundwater recharge in the Javanroud, Kermanshah karst region, was suggested. Given that the APLIS method was applied for the first time in Javanroud, Kermanshah region, it needs to be calibrated with AHP and TOPSIS methods. Finally, the results obtained from comparing the different weighting methods (i.e., APLIS, AHP and TOPSIS) with the matching map of fault and spring showed that the TOPSIS method was better matched with the fault and spring maps. Moreover, the collected data regarding water resources in this region show that the most important resource in this region is spring that has relatively high discharge. On the other hand, the average precipitation in this region (approximately $700 \mathrm{~mm}$ ) is 2 or 3 times more than the average precipitation in Iran, which is around $250 \mathrm{~mm}$. This conclusion in turn emphasises the high potential of recharge in this area.

\section{Acknowledgements}

The authors wish to thank the Water Resources Management Institute of Iran and Water Research Institute for providing data and supporting this research. We gratefully thank two anonymous reviewers and for their valuable comments which helped to improve the quality of the paper.

\section{References}

Andreo B, Vías J, Durán J J, Jiménez P, López-Geta J A and Carrasco F 2008 Methodology for groundwater recharge assessment in carbonate aquifers: Application to pilot sites in southern; Spain Hydrogeol. J. 16 11-25.

Andreo B, Vías J M, Mejías M, Ballesteros B J and Marín A I 2007 Estimation of the recharge by APLIS method in the Jurassic aquifer of El Maestrazgo (Castellón, NE Spain); In: II international symposium on coastal aquifers; Almeria, Spain.

Andreu J M, Alcala' F J, Vallejos A and Pulido-Bosch A 2011 Recharge to mountainous carbonated aquifers in SE Spain: Different approaches and new challenges; J. Arid Environ. 75(12) 1262-1270.

Farfan H, Corvea J L and De Bustamante I 2010 Sensitivity analysis of APLIS method to compute spatial variability of karst aquifers recharge at the National Park of Viñales (Cuba); In: Advances in research in karst Media, Springer, Berlin, pp. 19-24.

Ford D C and Williams P W 2013 Karst hydrogeology and geomorphology; John Wiley \& Sons, Hoboken.

Gerner A, Schütze N and Schmitz G H 2012 Portrayal of fuzzy recharge areas for water balance modelling - A case study in northern Oman; Adv. Geosci. 31 1-7.

Giorgi F and Lionello P 2008 Climate change projections for the Mediterranean region; Global Planet. Change 63(2) 90-104.

Gleeson T, Wada Y, Bierkens M F and Van Beek L P 2012 Water balance of global aquifers revealed by groundwater footprint; Nature 488 197-200.

Guardiola-Albert C, Martos-Rosillo S, Pardo-Igúzquiza E, Durán Valsero J J, Pedrera A, Jiménez-Gavilán P and Liñán Baena C 2015 Comparison of recharge estimation methods during a wet period in a karst aquifer; Groundwater 53(6) 85-95.

Hartmann A, Goldscheider N, Wagener T, Lange J and Weiler M 2014 Karst water resources in a changing world: Review of hydrological modeling approaches; Rev. Geophys. 52(3) 218-242.

Kardan Moghaddam H, Jafari F and Javadi S 2017 Vulnerability evaluation of a coastal aquifer via GALDIT model and comparison with DRASTIC index using quality parameters; Hydrol. Sci. J. 62 137-146.

Kirn L, Mudarra M, Marín A, Andreo B and Hartmann A 2017 Improved assessment of groundwater recharge in a Mediterranean karst region: Andalusia, Spain; In: EuroKarst 2016, Neuchâtel, Springer, pp. 117-125.

Lamoreaux P E 1991 History of karst hydrogeological studies; In: Proceedings of the international conference on 
environmental changes in karst areas, IGU-UIS, Italy, pp. 15-27.

Lerner D N, Issar A S and Simmers I 1990 Groundwater recharge: A guide to understanding and estimating natural recharge; Heise, Hannover.

Marín A I 2009 The application of GIS to evaluation of resources and vulnerability to contamination of carbonated aquifer: Test site Alta Cadena (Malaga province); PhD Thesis, University of Malaga, Spain.

Martos-Rosillo S, Rodríguez M, Moral F, Cruz-Sanjulián J J and Rubio J C 2009 Analysis of groundwater mining in two carbonate aquifers in Sierra de Estepa (SE Spain) based on hydrodynamic and hydrochemical data; Hydrogeol. J. 17(7) 16-17.

Mohammadi Z and Field M 2009 On the temporal behavior of karst aquifers, Zagros region, Iran: A geostatistical approach; J. Caves Karst Stud. 71(3) 210226.

Corresponding editor: ABhiJit MukherJeE
Neshat A and Pradhan B 2017 Evaluation of groundwater vulnerability to pollution using DRASTIC framework and GIS; Arab. J. Geosci. 10(22) 501.

Neshat A, Pradhan B, Pirasteh S and Shafri H Z 2014a Estimating groundwater vulnerability to pollution using a modified DRASTIC model in the kerman agricultural area, Iran Environ. Earth Sci. 71(7) 19-31.

Neshat A, Pradhan B and Shafri H Z 2014b An integrated GIS based statistical model to compute groundwater vulnerability index for decision maker in agricultural area; J. Indian Soc. Remote J. 42 77-88.

Portmann F T, Döll P, Eisner S and Flörke M 2013 Impact of climate change on renewable groundwater resources: Assessing the benefits of avoided greenhouse gas emissions using selected CMIP5 climate projections; Environ. Res. Lett. 8(2) 024023.

Yeh H F, Lee C H, Hsu K C and Chang P H 2009 GIS for the assessment of the groundwater recharge potential zone; Environ. Geol. 58(1) 85-95. 